\title{
Adding XML to the MIS Curriculum: Lessons from the Classroom
}

\author{
William P. Wagner \\ Villanova University, \\ Villanova, PA, USA
}

william.wagner@villanova.edu

\author{
Vik Pant \\ SAP AG, Newtown Square, \\ $P A$, USA
}

vik.pant@sap.com

\author{
Ralph Hilken \\ Artige Company, Narvon, PA, USA
}

\author{
ralph.hilken@artige.com
}

\section{Executive Summary}

eXtensible Markup Language (XML) is a new technology that is currently being extolled by many industry experts and software vendors. Potentially it represents a platform independent language for sharing information over networks in a way that is much more seamless than with previous technologies. It is extensible in that XML serves as a "meta" language - one that defines the rules for creating specific vocabularies for different industries and applications. At this point, two to five new industry vocabularies are being created each week. Major XML applications are now being defined for finance, accounting, supply chain management, e-commerce, and other functional areas in business. While it is still in its early stages of development, it is unclear how the MIS curriculum and that of the business school in general should react to this new technology. This paper will provide some background for the study of XML and will suggest how the study of XML can be integrated into the MIS curriculum. To aid in this process, three sample exercises are also presented that have been developed and tested in the classroom.

Keywords: XML, MIS curriculum, XBRL, VoiceXML.

\section{Introduction}

One of the main functions of MIS faculty is to carefully choose topics for the MIS curriculum that will give students the most powerful and complete set of skills and knowledge within the restraints of the available resources. Currently, a fairly pervasive technology is called eXtensible

Material published as part of this publication, either on-line or in print, is copyrighted by the Informing Science Institute. Permission to make digital or paper copy of part or all of these works for personal or classroom use is granted without fee provided that the copies are not made or distributed for profit or commercial advantage AND that copies 1) bear this notice in full and 2) give the full citation on the first page. It is permissible to abstract these works so long as credit is given. To copy in all other cases or to republish or to post on a server or to redistribute to lists requires specific permission and payment of a fee. Contact Publisher@InformingScience.org to request redistribution permission.
Markup Language or XML. In a world of disparate computing technologies and oft divergent software applications $\mathrm{XML}$ is fast becoming a universal language for data representation (Yang, 2005). Like most new tools, in the beginning its actual value to businesses may be apparent to only a few keen observers of technology trends. XML allows companies to standardize their information and, at a higher level, lets in- 
dustries standardize their information needs. When utilized correctly, XML-based applications will decrease transaction costs, thus enhancing the firm's potential for profitability (A. N. K. Chen, LaBrie, \& Shao, 2003). It has even been suggested that its impact will be so important that companies not involved in setting the standards in their respective industry will be at a competitive disadvantage similar to that which arose at the advent of the Web, when some companies had a Web presence and others did not (Ray, 2002). The rapid growth of XML-formatted documents has forced all the major database vendors to include XML handling capabilities in the most recent versions of their products (Babcock, 2006).

Judging by the amount of press that XML is getting, this trend seems to be gaining even more momentum. One researcher has claimed that XML is a critical driver in the growth of web services in e-business (M. Chen, 2003). If one accepts that the usage of XML is going to continue to grow in business then it is incumbent upon educators to update their curricula to reflect this fact. But just what is XML and how should it be taught in the MIS curriculum? This article will attempt to address these two issues and suggest some specific ways to begin integrating it into MIS coursework. As such, this is a conceptual paper that is intended to generate interest and debate on this topic.

\section{What is XML?}

XML, or eXtensible Markup Language, is a meta-language based on an earlier markup language called Standard Generalized Markup Language (SGML). Meta is derived from a Greek word that means "above, higher, or beyond," in the sense that it transcends normal language. So as a metalanguage, XML is beyond normal computer languages because it provides the rules that facilitate the development of industry- and application-specific markup languages. These specialized XML languages allow for the transmission of data between users regardless of the platform, communication channel, operating system, or software application being used.

Simply put, XML is a markup language that uses paired tags to describe data. The crucial difference between XML and other pre-existing markup languages such as HTML is that it uses tags to assign meaning to the actual content being marked up. This allows applications to be developed that truly separate the data content from the formatting and structure aspects of the document. As stated by the World Wide Web consortium (W3C) itself, XML

$" .$. is primarily intended to meet the requirements of large-scale Web content providers for industry-specific markup, vendor-neutral data exchange, media-independent publishing, one-on-one marketing, workflow management in collaborative authoring environments, and the processing of Web documents by intelligent clients.... The language is designed for the quickest possible client-side processing consistent with its primary purpose as an electronic publishing and data interchange format (World Wide Web Consortium, 1998).

Since XML was recommended by the W3C in February 1998, over 200 new XML languages have been established, with everything from Astronomical Instrument Markup Language (AIML) to Theological Markup Language (TML). Currently, two or three new XML languages are developed each week, and according to Erdmann and Studer (1999), "Dozens, maybe hundreds of applications of this flexible language have been developed and more will surely follow."

As XML standards become more developed and authoring tools become more widespread, its relative value is becoming clearer. In the past year alone, there were over 30 IT conferences devoted to various XML applications and topics. But one of the most common misinterpretations about XML today is that it is just a new language for web pages and e-commerce. More fundamentally, it functions as a messaging protocol or middleware for the sharing of information. 


\section{Methodology}

The decision to include the study of XML in the MIS curriculum should not be done without due consideration of all the appropriate factors. In this case, the authors read a wide variety of industry publications and spoke with IT professionals and alumni involved in different aspects of the IT profession. At the time, the study of HTML was a standard component of many Computer Science and MIS curricula across the globe. XML was being touted by many as the next generation language for e-commerce that would replace HTML. In fact, XML is one of the main enabling technologies of the new Service Oriented Architectures (SOAs) that are becoming increasingly popular today (Henningsson, Svensson, \& Vallen, 2007).

Operating on the premise that MIS students should be exposed to current technologies, it was decided that because XML was becoming so prevalent in business it should be included in some form in the current MIS curriculum. The next issue was to determine which XML vocabularies were the most important ones to study. After surveying the existing curricula and also informally discussing this matter with alumni and friends of the program, it was determined that students should have a basic understanding of XML concepts and these should be illustrated with XML applications from frequently used XML vocabularies; these included XBRL and VoiceXML. In the business context of the MIS curriculum, these were determined to be the most relevant. This is especially true since many of the MIS majors are also majoring in Accounting and are frequently hired into the large Accounting/MIS consulting firms.

\section{XML and the MIS Curriculum}

In order to get a solid understanding of XML, there are number of basic concepts and technologies that students should master. This is especially true if they are going to continue and study a particular industry-level vocabulary such as XBRL or FinXML. The problem is that if one were to simply list all the related XML concepts and technologies it might include such diverse topics as Namespaces, Cascading Style Sheets, Schemas, DTDs, XSL, XSLT, XPath, and many others (Smith, 2002). Most of the professional press books on XML talk about these technologies but it often comes across as a random walk through them. And this problem is further complicated by the fact that some people are simply going to be project managers or users and don't need to be totally immersed in XML application development

Since it is a relatively new subject-matter in the classroom, it is often difficult for students to understand the full implications of it. It is good to start with a fundamental distinction regarding the nature of any document. Students may not have realized it, but all documents consist of content, formatting, and structure. A simpler distinction between these components can be considered as the division between content and its representation (Cap, 2000). While the ideas of document content and formatting are obvious to most students, many have given little thought to the notion of the structure of a document. This can be easily demonstrated by holding up a memo or a table of contents for a book. Each of these can be recognized at a distance by the class, since students are familiar with the standard structure of these documents. Once this idea of the digital document is introduced then it is possible to illustrate that XML enables developers to separate out these three parts of a document and create special tags for document content.

This idea of the digital document can be further illustrated by examining how HTML documents look. Even if students have not studied or programmed in HTML before, they quickly recognize the paired tags in sample documents such as a resume. One can then pose the question "What is wrong with HTML?" At this point the instructor should point out the fact that the HTML code inter-mixes content with formatting and also structure whereas XML makes it "possible to separate between issues of content and issues of presentation" (Kallenberg \& van de Ven, 2004). This then begs the question about "why this might matter?", and the instructor can then compare how a 
search will search an HTML resume as opposed to an XML resume that has specific tags to indicate job skills such as "XML" and "Java" that might be of interest to potential employers.

To explain this in greater detail the instructor can emphasize that as a language HTML contains instructions regarding how the content contained in an HTML document should be rendered on a client's user interface (such as on a web browser). There is no concept within HTML to enable semantic analysis of content contained within an HTML document. It is not possible for a system parsing an HTML document to natively discern the higher level meaning of the content contained within it. For instance, an HTML resume will contain all the information of a person's resume; however, without additional logic or processing an external system will not be able to distinguish the information pertaining to that person's work experience from her educational background. On the other hand an XML document will contain similar information between a well-organized structure and classification system of tags (Buendía, Benlloch, Gil, \& Agustí, 2001). An external system will be able to distinguish the information categorized as a person's work experience from her educational background simply by seeking it within tags that encapsulate it (usually by name).

Further XML education can be structured around the basic systems model. In other words, to develop an XML application, students can look at how XML structures data inputs, how they are parsed by different software applications, and how the data are filtered and formatted as output for a wide variety of applications. According to Nierman and Jagadish (2002), "Document Type Definition (DTD) information establishes a structure for an XML document", and building on that idea, on the data input side students will usually start with the idea of how a DTD helps to provide structure to the data in the application. This same idea can be conveyed by examining the use of XML schemas, which have recently been popularized as an alternative to DTDs which have internal limitations. It will also be important at this point to introduce the notion of XML Namespaces and data modeling and how it might relate to the structure of a relational database table.

Once students are familiar with how XML content is structured for parsing then it is reasonable to introduce them to the many different output technologies. If they already have experience developing HTML applications, it is usually easiest for them to begin with the Cascading Style Sheet technology. Beyond this there are a wide variety of somewhat confusing XML output technologies that may be of use in developing an application. The leading ones include XHTML, XSL, XSLT, XSLT-FO, XPath, and SAX. It is advisable to include the basics of XSL and XSLT if the instructor wants the students to be able to do some basic outputting control for their applications (Wagner \& Hilken, 2003).

As a meta language, XML could be a valuable tool in helping to integrate various functional area applications that might be covered. Specific XML vocabularies such as XBRL, FinXML, and ebXML have direct implications in Accounting, Finance, and e-commerce. This especially obvious when one considers how XML is being used as a messaging technology by Microsoft in order to link up applications in its new .NET architecture. One also sees this role in such XML-based technologies as SOAP and XML-RPC.

At this point, the use of XML in the MIS curriculum is quite rare, but XML may be an important component in a variety of different MIS classes. Conceivably it could be used to enhance the typical database class, systems analysis and design, and of course the e-commerce and web development classes. Within the MIS curriculum almost all of the standard courses may reasonably include the study of XML concepts to different degrees. For example in the standard database management course, after studying a few XML basics, students could be shown how a basic table structure can be "wrapped" with XML markup. Furthermore, students will be able to grasp the capability of XML at integrating databases (Bergeron, 2004). This is important in migrating data- 
base content to the web and publishing catalogs to the Internet. One indication of its importance for databases is the fact that the American National Standards Institute (ANSI) is working on a version of structured query language (SQL) that supports querying XML documents (Babcock, 2006).

It should be noted also that the cost of including XML in the MIS curriculum is low since it does not involve the purchase of any new hardware or software. By definition, XML is platformindependent, and students can simply save files edited in Notepad as XML files or they can download a number of free XML editors such as Microsoft's XML Notepad. Instructors should know that they can choose from a variety of tools for displaying XML documents. Today almost every web browser supports XML (eg. Internet Explorer, Mozilla FireFox, Opera).

Within the MIS curriculum, many instructors have developed a variety of hybrid classes in order to cover more ground. One example might be how the standard Systems Analysis and Design class can be "web-ified" by having the students focus on web related development projects. This is a case where XML might also be a good fit. Instead of doing the typical HTML design projects for this type of class, these can be updated using a variety of XML technologies such as DTDs, CSS, and XPath. What is good is the fact that XML and HTML are not meant to be two mutually exclusive technologies. In fact, cascading style sheets (CSS) are used by both for outputting documents and most HTML format commands are still valid when applied to XML.

XML can be included as a strong supplement to information management courses in a curriculum, as one of its primary applications is the meaningful exchange of information. Since XML is useful in assigning context to content, this capability can be highlighted to business students in explaining the difference between its purely technical constructs and its applications and implementation. The notion of tags encapsulating data enables the assignment of context to content because, according to Engelhardt, Hildebrand, Kárpáti, Rack, and Schmidt (2002), "in formal terms the context of a component is denoted by the data immediately embedding it." This will assist information management courses, for example, in imparting more than just a technical understanding of the operations of database systems but rather convey an understanding of the processes involved in the semantic analysis of data.

Furthermore, since XML can be output (generated) and input (parsed) using almost all of the common programming languages it can be used to enhance standard software programming classes within an MIS program's course offerings. According to Brusilovsky (2003), "the presence of XML with a wide range of supporting tools makes it especially easy for the developers to get their design inside the computer." Institutions that favor the inclusion of Java-centric software programming classes in their MIS curriculum can explore the possibilities of incorporating JAXP (Java API for XML Processing) as an appropriate entry point for students into the domain of J2EE from core Java. Other institutions that find their MIS curriculums contain more Microsoftoriented software programming courses can use XML to highlight and segue into the Microsoft.NET platform - an integral part of which is a set of XML-based technologies.

MIS programs can choose to teach XML in a vendor-neutral framework or with a productspecific focus as it is a standard and not a product. There has been an upsurge in the adoption of XML in the industry over the past few years, and along with that have come to market a variety of new textbooks, professional literature, and other instructional materials pertaining to this subject matter.

\section{Sample XML Exercises}

It is important when teaching XML to quickly relate the concepts to a practical example since it is easy to lose the students' interest. One of the quickest and easiest examples to do initially with 
students is to show them how a basic document, such as a memo, can be converted into XML. To begin with, students should map out the structure, or what is sometimes called the "document model", of a typical memo. This might look something like the diagram in Figure 1.

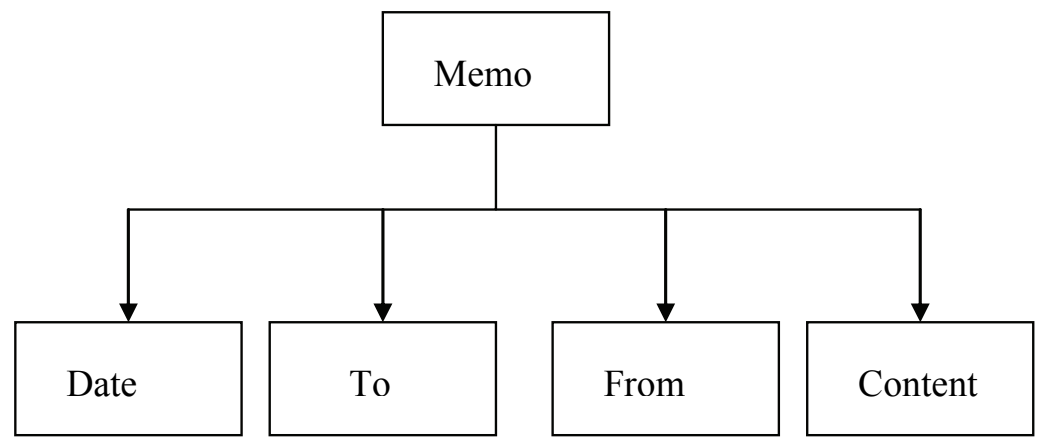

Figure 1: Sample Document Structure

Once this done then students can be instructed in how to convert the model into a set of nested elements in the DTD (see Figure 2).

$<$ !ELEMENT
$<$ emo (Date, TO, FROM, Content) $>$
$<$ !ELEMENT Date (\#PCDATA) $>$
$<$ !ELEMENT TO (\#PCDATA) $>$
$<$ !ELEMENT FROM (\#PCDATA) $>$
$<$ !ELEMENT Content (\#PCDATA) $>$
Figure 2:

Using XML markup, the actual content of this memo example might look like the example presented in Figure 3. Notice that it references the DTD created in Figure 2.

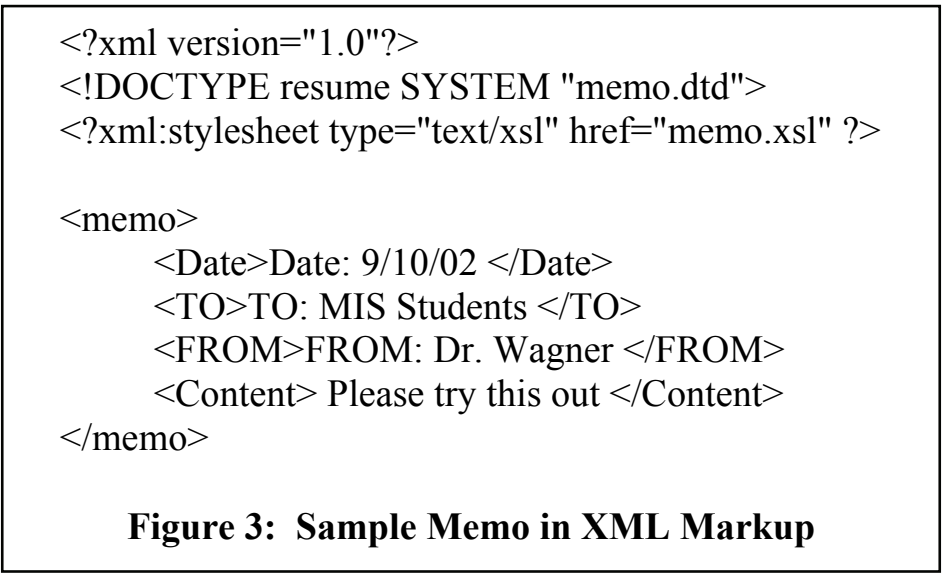

If the instructor wants to illustrate a simple but complete XML application, the memo above can be output using XSL. This is referenced in the prolog of Figure 3. A sample of how this might be used is illustrated in Figure 4. 


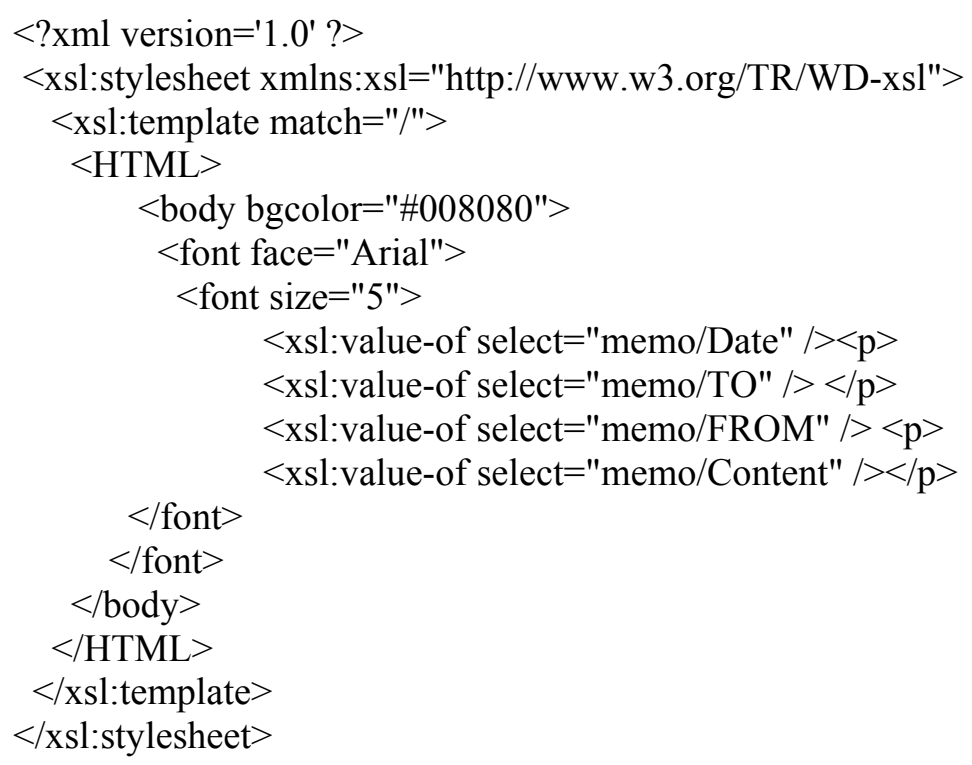

Figure 4: Output of Memo Using XSL

All of the files above can be created using the basic Notepad application and saved with the appropriate file name and extension (i.e. .dtd, .xml, .xsl). It should be remembered that the files must be viewed using Internet Explorer 5.0 or one of its newer versions.

If the instructor wishes to present an example of an industry-level XML vocabulary, one of the most prominent ones today is eXtensible Business Reporting Language or XBRL. There are nearly twenty different Working Groups within the XBRL consortium that are developing specifications for documents as varied as Balance Sheets, Income Statements, SEC reports, and even Audit Worksheets. Within the industry, the hopes for XBRL are very high that this technology will help impose more rigor in standardizing, generating, and sharing corporate financial data. One proposed sample element for a US GAAP financial statement note might look like Figure 5 in XBRL:

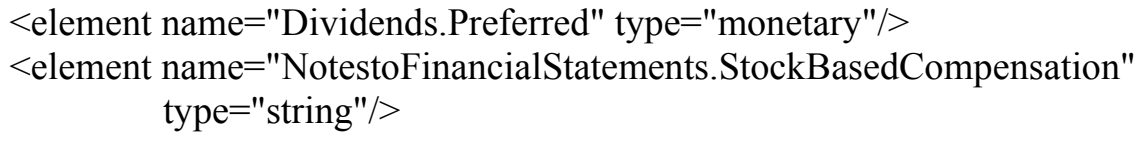

Figure 5: Sample Element for GAAP Financial Statement Note

Other XBRL examples can be found at http://www.xbrlsolutions.com. XBRL is rapidly gaining acceptance among CPA firms and will soon be built into most of the software used for generating reports. Some banks are even trying to speed up the process by offering lower loan rates to corporate customers who file loan documents using standard XBRL.

One interesting example of how XML can function as a middleware tool was developed using VoiceXML tools. VoiceXML allows the use of voice-recognition technology to interact with the Internet. This example almost always causes students to think twice about the power of XML. In one sense all this application does is to help users to connect to a database, perform basic searching, and output the results to the user - ostensibly not very impressive. But if you take into account the fact that it is totally voice-driven and all the interaction between the human and the computer is performed via voice commands and voice outputs, then this gets the students' atten- 
tion. This is especially true since all of them are likely to be avid users of wireless and cell phone technologies. For instructors, what is nice is the fact that this does not require a lot of resources or proprietary technology. VoiceXML is one of the newer in the family of eXtensible Markup Languages. It was conceptualized and developed by many information technology and application networking organizations including Cisco, IBM, Lucent Technologies, and Motorola heading the project.

This application works using a combination of three key technologies; Text-to-Speech (TTS), Speech-to-Text (voice recognition), and the XML-powered Relational DB processing. The first two are subsets of the VoiceXML technology and the latter is XML-based database operation. Simply put, this application uses VoiceXML to prompt the user for input and then parses the user input/instructions via VXML voice recognition engines into a query. Then it queries the relational database via XML packets using the criteria specified by the user and finally outputs the results from the database search operation via the VoiceXML TTS engine.

According to Hocek and Cuddihy (2002), "VoiceXML is being used in applications such as voice portals, where automated voice services can be accessed over the phone." Such VoiceXML

driven applications are a boon for the service and support industry, primarily minimizing human requirements for call center operations. Citibank and Chase are two of the many financial institutions that now allow its account holders to conduct basic banking via the telephone. USAir and KLM in the airline industry allow for the tracking of lost or misplaced baggage via such a technology. Deloitte and Touche and also KPMG are pilot testing programs that utilize an intersection of XBRL and VXML for convenient accounting information reporting. Yahoo and BeVocal, two email providers, allow for the browsing and sending of mail from regular email addresses via the telephone using voice. ETrade and Power Fidelity are spearheading initial testing of stock trading applications based on such voice-based computing technology. The possibilities in all kinds of varied deployment scenarios are endless.

In the classroom, many students will have brought cell phones with them so instructors can have them access and execute this application, by calling the number shown in Table 1 and following the instructions in the table.

Table 1. VoiceXML Instruction Set 1.

\begin{tabular}{|l|l|}
\hline Device & Telephone - Regular/Cellular \\
\hline Telephone Number & 1.877 .33$. VOCAL or 408.907.7328 \\
\hline Step 1: & $\begin{array}{l}\text { Speak or type “2028021" (telephone keypad) when prompted for User ID } \\
\text { or User Name }\end{array}$ \\
\hline Step 2: & Speak or type "1234” (telephone keypad) when prompted for Pin. \\
\hline Step 3: & The voice-driven menu is activated \\
\hline
\end{tabular}

Once successfully connected, perform the steps in Table 2.

A basic VoiceXML editor can be downloaded off the BeVocal.com web site and provides instructions to help students to create the VXML markup file that is needed to help link up the various technologies required to make this application work. 
Table 2. VoiceXML Instruction Set 2.

\begin{tabular}{|l|l|}
\hline Step 1: & Prompted for input, say "Teachers" or "Students" \\
\hline Step 2: & $\begin{array}{l}\text { If you said "Students" skip to Step 5 } \\
\text { If you said "Teachers", follow instructions, and speak a Professor's last } \\
\text { name. In this demo, you can say -> "Wagner", "Sloane", "Borden" or } \\
\text { "Heck". }\end{array}$ \\
\hline Step 3: & After prompting, say "Department" or "Status" \\
\hline Step 4: & Enjoy the results of your query. \\
\hline Step 5: & $\begin{array}{l}\text { If you said "Students", follow instructions, and speak a Student's first } \\
\text { name. In this demo, you can say -> "Vic", "Alex", "Ted" or "Shane". }\end{array}$ \\
\hline Step 6: & After prompting, say "Email" or "Major" \\
\hline Step 7: & Enjoy the results of your query. \\
\hline
\end{tabular}

In order to connect to the database, this VoiceXML application uses an ASP script that queries the database (based on initial input VXML) and constructs results VXML page on the fly. So this application is a collection of three files: the initial VXML file for user input, the ASP database querying file (using ADO RDS), and the final VXML results file.

\section{Conclusion}

$\mathrm{XML}$ is a new technology that is rapidly having a major impact on information system applications being developed in most industries. A search of XML.org reveals that new XML vocabularies are being added every week for every imaginable industry from insurance and banking to manufacturing and aeronautics. Many former students are also involved in helping set up new XML standards for their respective industries. With hundreds of XML-based vocabularies out there it becomes very difficult for instructors to know which one to pick and which concepts to focus on. Because of its broad impact, it is important not to teach it just as new generation of HTML but as a technology that can be used to integrate a wide variety of related technologies to create innovative new applications.

This paper has presented an overview of XML and some of these technologies and suggests some ways in which it can be introduced into the standard MIS curriculum. For those who want students to be able to develop complete XML applications it has suggested some of the key ones that need to be introduced.

Finally, three sample applications were introduced that illustrated the breadth of XML applicability. The first one, the conversion of a simple document such as a memo helps to illustrate some basic XML concepts such as elements, structure and how they are represented by a DTD. The second one taken from the accounting profession, shows how XML rules have been used to develop an industry vocabulary called XBRL. This vocabulary itself has numerous working groups and is having a wide impact on the production of standard accounting and financial reports.

The last example further illustrates the power of XML by showing how it can be used as a middleware technology to integrate a variety of voice input/output technologies. This is one that especially gets students attention because it combines wireless and voice recognition technologies in a way that may be new to them. 
For instructors, XML is a powerful new technology that doesn't require a lot of resources to introduce into the classroom since it is by nature not dependent on any one platform. It also has implications for all the functional areas within a business school. There are also a variety of parsers and XML editors that are free to students and instructors. However, until recently, there were only a few textbooks available for instructors that would help unravel the potentially confusing array of competing technologies. Further work at developing texts and interesting examples is needed for the full impact of this exciting new technology to be felt on the MIS curriculum.

\section{References}

Babcock, C. (2006, July 31). Databases get better at managing XML data. Information Week.

Bergeron, B. (2004). Essentials of XBRL: Financial reporting in the 21st century. Indianapolis, IN: John Wiley \& Sons. p 8.

Brusilovsky, P. (2003). Developing adaptive education hypermedia systems: From design models to authoring tools. In T. Murray, S. Blessing, \& S. Ainsworth (Eds.), Authoring tools for advanced learning technologies. NL: Kluwer Academic Publishers.

Buendía, F., Benlloch, J. V., Gil, J. A., \& Agustí, M. (2001). XEDU: A XML-based framework for developing didactic resources. 12th EAEEIE conference, Nancy, 2001.

Cap, C. H. (2000). XML goes to school: Markup for computer assisted learning and teaching. European Journal of Open and Distance Learning. Retrieved from http://www.eurodl.org/materials/contrib/2000/icl2000/cap.html

Chen, M. (2003). Factors affecting the adoption and diffusion of XML and Web services standards for Ebusiness systems. International Journal of Human-Computer Studies, 58(3), 259-279.

Chen, A. N. K., LaBrie, R. C., \& Shao, B. B. M. (2003). An XML adoption framework for electronic business. Journal of Electronic Commerce Research. 4(1), 1-14.

Engelhardt, M., Hildebrand, A., Kárpáti, A., Rack, T., \& Schmidt, T. C. (2002). Educational content management - A cellular approach. Proceedings of the International Workshop "Interactive Computer aided Learning" ICL 2002, Kassel University Press.

Erdmann, M., \& Studer, R. (1999). Ontologies as conceptual models for XML documents. Proceedings of the 12th International Workshop on Knowledge Acquisition, Modelling and Management (KAW'99), Banff, Canada.

Henningsson, S., Svensson, C., \& Vallen, L. (2007). Mastering the integration chaos following frequent M \& As: IS integration with SOA technology. Proceedings of the $40^{\text {th }}$ Hawaii International Conference on System Sciences - 2007.

Hocek, A., \& Cuddihy, D. (2002). Definitive VoiceXML. Upper Saddle, NJ: Prentice Hall PTR.

Kallenberg, A. J., \& van de Ven, M. J. J. M. (2002). The new educational benefits of ICT. Higher Education: Proceedings; Rotterdam: Erasmus Plus BV

Nierman, A., \& Jagadish, H. (2002). Evaluating structural similarity in XML documents. Proceedings of 5 th International Workshop on the Web and Databases, Madison, WI.

Ray, S. (2002). Interoperability standards in the semantic web. Journal of Computing and Information Science in Engineering. 2(1), 65-69.

Smith, D. (2002). An XML learning framework. Proceedings of XML Europe 2002, May 20-23.

Wagner, W., \& Hilken, R. (2003). Introduction to applied XML for business. Upper Saddle, NJ: Prentice Hall PTR.

World Wide Web Consortium. (1998). The world wide web consortium issues XML 1.0 as a W3C recommendation. Retrieved from http://www.w3.org/Press/1998/XML10-REC 
Yang, H. (Ed.) (2005). Advances in UML and XML-based software evolution. Hershey, PA, USA: Idea Group Publishing. p 257.

\section{Biographies}

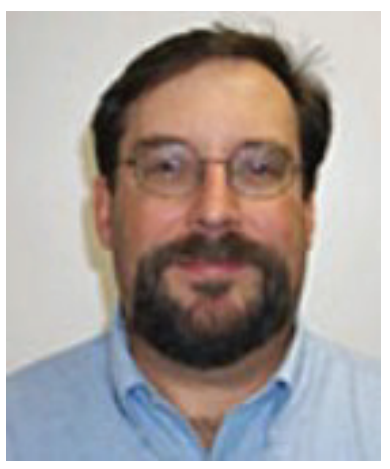

Professor Wagner has been teaching, consulting, and conducting research in Information Systems since 1988. He has been on the faculty of Villanova University since 1991 and has developed many innovative new courses and been a leader in the use of new teaching technologies. His research includes topics in the areas of Artificial Intelligence, Enterprise Resource Planning (ERP) systems and E-Commerce and has appeared in internationally known journals such as Expert Systems, Journal of Computer Information Systems, Internet Research, and Knowledge-Based Systems. He recently co-authored the first university-level text book on eXtensible Markup Language (XML) entitled Introduction to Applied XML Technologies for Business (Prentice Hall, 2003), and the first text on Customer Relationship Management (CRM) entitled, Customer Relationship Management (CRM): A People, Process, and Technology Approach (Thomson Publishing, 2007).

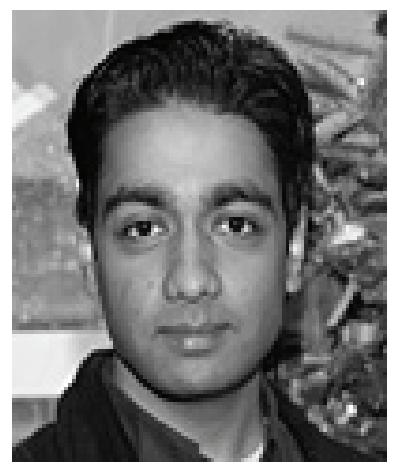

Mr. Pant is a systems integrator specializing in SAP applications and technologies. He is a graduate from the College of Commerce and Finance at Villanova University with degrees in Management Information Systems and Finance. He is currently affiliated with SAP America as a Solution Engineer and works closely with several research institutions. His research interests include enterprise computing, data interchanges and artificial intelligence. His current research is focused on customer relationship management and strategic enterprise management.

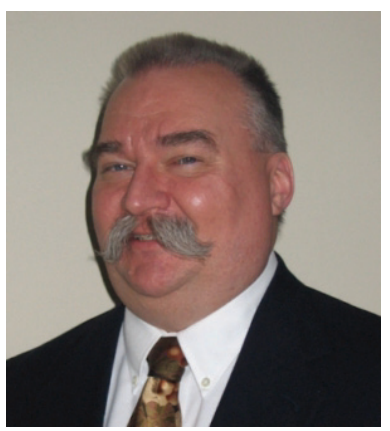

Mr. Hilken is an IT consultant and strategist, focusing on system architecture and rescuing systems and facilities that have not met their design potential. Over the past $25+$ years he has acquired a broad background in engineering, IT, manufacturing and education, in the chemicals, metals, printing, publishing and educational industries, providing him with an advantage in working on large system integration projects. In addition, he is also the proprietor of an independent software business, Artige Company. Mr. Hilken has taught as an adjunct professor at Villanova University, in the School of Business. He taught various IT and operations courses, plus authored an introductory textbook on XML. Mr. Hilken holds a BE from Stevens Institute of Technology, and a MBA from Villanova University. 